\title{
Clinical impact of forced vital capacity on exercise performance in patients with chronic obstructive pulmonary disease
}

\author{
Seong Mi Moon ${ }^{1 \#}$, Jun Hyeok Lim ${ }^{2 \#}$, Yun Soo Hong ${ }^{3}$, Kyeong-Cheol Shin ${ }^{4}$, Chang Youl Lee \\ Do Jin Kim ${ }^{6}$, Sang Haak Lee ${ }^{7}$, Ki Suck Jung ${ }^{8}$, Chang-Hoon Lee', Kwang Ha Yoo ${ }^{10}$, Hyun Lee ${ }^{11}$, \\ Hye Yun Park ${ }^{12}$
}

${ }^{1}$ Division of Pulmonary and Critical Care Medicine, Department of Medicine, Samsung Changwon Hospital, Sungkyunkwan University School of Medicine, Changwon, South Korea; ${ }^{2}$ Division of Pulmonology, Department of Internal Medicine, Inha University Hospital, Inha University School of Medicine, Incheon, South Korea; ${ }^{3}$ Department of Epidemiology and Welch Center for Prevention, Epidemiology, and Clinical Research, Johns Hopkins University Bloomberg School of Public Health, Baltimore, MD, USA; ${ }^{4}$ Division of Pulmonology and Allergy, Regional Center for Respiratory Disease, Yeungnam University Medical Center, Daegu, South Korea; ${ }^{5}$ Division of Pulmonary, Allergy and Critical Care Medicine, Department of Internal Medicine, Chuncheon Sacred Heart Hospital, Hallym University, Chuncheon, Gangwon-do, South Korea; ${ }^{6}$ Department of Internal Medicine, Soonchunhyang University Bucheon Hospital, Bucheon, South Korea; ${ }^{7}$ Division of Pulmonary, Critical Care and Sleep Medicine, Department of Internal Medicine, Eunpyeong St. Mary's Hospital, College of Medicine, Department of Internal Medicine, The Catholic University of Korea, Seoul, South Korea; ${ }^{8}$ Division of Pulmonary Medicine, Department of Internal Medicine, Hallym University Sacred Heart Hospital, Hallym University Medical School, Anyang, South Korea; ${ }^{9}$ Division of Pulmonary and Critical Care Medicine, Department of Internal Medicine, Seoul National University Hospital, Seoul, South Korea; ${ }^{10}$ Division of Pulmonary and Critical Care Medicine, Department of Internal Medicine, Konkuk University Medical Center, Konkuk University School of Medicine, Seoul, South Korea; ${ }^{11}$ Department of Internal Medicine, Hanyang University College of Medicine, Seoul, South Korea; ${ }^{12}$ Division of Pulmonary and Critical Care Medicine, Department of Medicine, Samsung Medical Center, Sungkyunkwan University School of Medicine, Seoul, South Korea

Contributions: (I) Conception and design: SM Moon, H Lee, HY Park; (II) Administrative support: H Lee, HY Park; (III) Provision of study materials or patients: SM Moon, JH Lim, YS Hong, H Lee, HY Park; (IV) Collection and assembly of data: SM Moon, JH Lim, YS Hong, H Lee, HY Park; (V) Data analysis and interpretation: SM Moon, JH Lim, YS Hong, H Lee, HY Park; (VI) Manuscript writing: All authors; (VII) Final approval of manuscript: All authors.

"These authors contributed equally to this work.

Correspondence to: Hye Yun Park. Division of Pulmonary and Critical Care Medicine, Department of Medicine, Samsung Medical Center, Sungkyunkwan University School of Medicine, Irwon-ro 81, Gangnam-gu, Seoul 06351, South Korea. Email: hyeyunpark@skku.edu; Hyun Lee. Division of Pulmonary Medicine and Allergy, Department of Internal Medicine, Hanyang University College of Medicine, 222 Wangsimni-ro, Seongdong-gu, Seoul, 04763, South Korea. Email: namuhanayeyo@hanyang.ac.kr.

Background: Forced vital capacity (FVC) has been suggested to be a good biomarker for decreased exercise performance in patients with chronic obstructive pulmonary disease (COPD). However, as FVC is highly correlated with forced expiratory volume in 1 second $\left(\mathrm{FEV}_{1}\right)$, the relationship between $\mathrm{FVC}$ and exercise capacity should be assessed within the category of FEV1, i.e., COPD severity. However, this was not considered in previous studies. Thus, limited data are available on the association between reduced FVC and exercise capacity measured by 6-min walk distance (6MWD) based on COPD severity.

Methods: We performed a cross-sectional study using data from the Korean COPD Subgroup Study (KOCOSS) cohort. We evaluated 1,386 patients with moderate $(n=895)$ and severe-to-very severe $(n=491)$ COPD. Reduced FVC was defined as FVC $<80 \%$ predicted and short $6 \mathrm{MWD}$ as $<350 \mathrm{~m}$. Multivariable logistic regression was used to evaluate the association between reduced FVC and short 6MWD.

Results: There were no significant differences in respiratory symptoms and quality of life between the patients with reduced FVC and those with preserved FVC. However, patients with reduced FVC had shorter 6MWD (30.5 cm in moderate and $34.5 \mathrm{~cm}$ in severe-to-very severe COPD) and higher BODE index scores than those with preserved FVC. The cubic spline model revealed $6 \mathrm{MWD}$ peaked around $93 \%$ predicted of FVC in moderate COPD, whereas FVC showed a positive association with $6 \mathrm{MWD}$ in severe-to-very severe 
COPD. Multivariable analyses showed that reduced FVC was significantly associated with short 6MWD in both moderate [adjusted odds ratio $(\mathrm{aOR})=1.44$, 95\% confidence interval (CI): 1.03-2.02] and severe-tovery severe (adjusted OR $=1.55,95 \% \mathrm{CI}: 1.01-2.40$ ) COPD.

Conclusions: Reduced FVC was significantly associated with shorter 6MWD in moderate-to-very severe COPD patients, suggesting that reduced FVC might be reflective of $6 \mathrm{MWD}$-measured exercise capacity in moderate-to-very severe COPD.

Keywords: Chronic obstructive pulmonary disease (COPD); 6-min-walk test (6MWT); forced vital capacity (FVC)

Submitted Mar 01, 2020. Accepted for publication Nov 04, 2020.

doi: $10.21037 /$ jtd-20-1098a

View this article at: http://dx.doi.org/10.21037/jtd-20-1098a

\section{Introduction}

Physical inactivity is an important predictor of chronic obstructive pulmonary disease (COPD) outcomes. COPD patients with physical inactivity have reduced healthrelated quality of life, increased hospitalization, and higher mortality than those with good exercise capacity (1-5). Physical activity can be assessed using various methods, such as questionnaire surveys, self-reported diaries, and objective measurements $(6,7)$. The 6 -min walk test $(6 \mathrm{MWT})$ is a well-known exercise test that is useful for stratifying the degree of exercise performance in COPD patients $(3,8-10)$. A short 6-min walk distance (6MWD) is strongly associated with reduced daily activity (8).

Spirometry is an essential and useful tool for diagnosing COPD, as well as for classifying its severity and prognosis (11). Although the forced expiratory volume in 1 second $\left(\mathrm{FEV}_{1}\right)$ has been widely used as a biomarker, recent studies have shown that forced vital capacity (FVC) could provide valuable information for both non-COPD and COPD patients. Accumulating evidence shows that reduced FVC is associated with multiple comorbid conditions (e.g., aging, cardiovascular disease, and obesity) and reduced exercise capacity in the general population (12-15). Several other studies on the COPD population revealed that FVC and $\mathrm{FEV}_{1}$ are correlated with exercise capacity based on measures such as $6 \mathrm{MWD}$, shuttle walk test distance, and peak maximum rate of oxygen consumption $\left(\mathrm{VO}_{2} \max \right)$ (16-20), and that reduced FVC is associated with behavior restriction, especially in those with moderate airflow limitations (21).

The above studies suggested that reduced FVC might be a good biomarker for predicting decreased 6MWD and behavior restriction. However, the relationship between reduced FVC and 6MWD in the COPD population is still inconclusive because previous studies evaluated a small number of patients and analyzed FVC as a continuous variable $(18,19)$. In addition, as $\mathrm{FEV}_{1}$ is one of the most significant factors affecting exercise capacity and $6 \mathrm{MWD}$, the severity of COPD needs to be considered for the evaluation of the relationship between FVC and 6MWD. However, this was not considered in previous studies $(18,19)$. Thus, in this study, we aimed to investigate the relationship between FVC and exercise capacity measured using $6 \mathrm{MWD}$, with stratification of the severity of airflow limitations, in a prospective observational COPD cohort.

\section{Methods}

\section{Study population}

The study population comprised patients from the Korean COPD Subgroup Study (KOCOSS) cohort (registered on ClinicalTrials.gov with identifier NCT02800499), which is an ongoing multicenter, prospective observational cohort of COPD that has included participants from 53 centers in South Korea since December 2011. The inclusion criteria were as follows: age $\geq 40$ years and post-bronchodilator $\mathrm{FEV}_{1} / \mathrm{FVC}$ ratio of $<0.7$. At the first visit, medical history information was collected, such as smoking status, patient-reported education level, medications including those already prescribed for COPD, and self-reported comorbidities taken from questionnaires. The modified Medical Research Council (mMRC) scores for dyspnea severity (22), COPD assessment test (CAT) scores (23), and scores from the COPD-specific version of St George's Respiratory Questionnaire (SGRQ-C) were assessed (24). Spirometry and $6 \mathrm{MWT}$ were performed at the time of enrolment. "History of asthma" was defined as patients' self-report of physician-diagnosis of asthma. All data were 


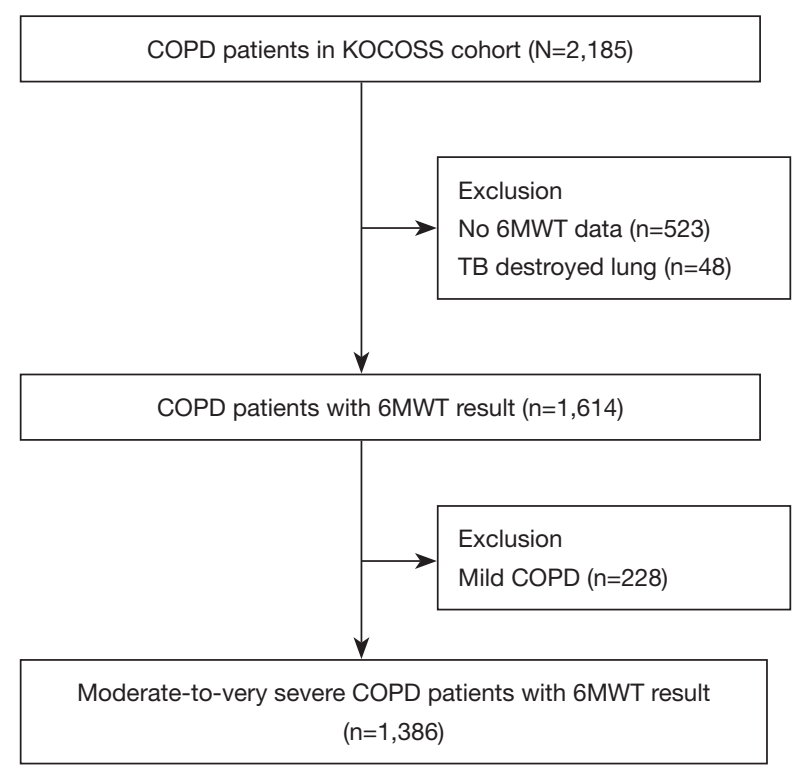

Figure 1 Study population. COPD, chronic obstructive pulmonary disease; KOCOSS, Korea COPD Subgroup Study; 6MWT, 6-min walk test; TB, tuberculosis.

documented in case report forms completed by physicians or trained nurses. The study was conducted in accordance with the Declaration of Helsinki (as revised in 2013). Written informed consent was obtained from all study patients. Ethics approval for this study was obtained from the institutional review boards of each center (Samsung Medical Center, IRB No. 2014-06-132). All methods were performed in accordance with the relevant guidelines and regulations.

Initially, 2,185 patients recruited from the KOCOSS cohort were eligible for this study. Patients who had no $6 \mathrm{MWD}$ data $(\mathrm{n}=523)$, those with tuberculosis-destroyed lungs, defined as lung destruction of one lobe or more due to tuberculosis infection (25) $(\mathrm{n}=48)$, and those with a mild degree of airflow limitation $(\mathrm{n}=228)$ were excluded. Patients who had only history of tuberculosis infection without lung destruction were not excluded in this study. Finally, 1,386 patients were included our analysis (Figure 1).

\section{Pulmonary function tests and disease severity}

Spirometry was performed according to the recommendations of the American Thoracic Society/ European Respiratory Society (26). All of the spirometric measures used included post-bronchodilator values for $\mathrm{FEV}_{1}$ and FVC. COPD severity was categorized according to Global Initiative for Chronic Obstructive Lung Disease grading system, as follows: moderate $[50 \%$ predicted (pred) $\leq \mathrm{FEV}_{1}<80 \%$ pred], or severe-to-very severe ( $\mathrm{FEV}_{1}$ $<50 \%$ pred) (11). Patients were further classified into the preserved FVC group (FVC $\geq 80 \%$ pred) and reduced FVC group (FVC $<80 \%$ pred) (21). We performed $6 \mathrm{MWT}$ according to the American Thoracic Society guidelines (27). Short $6 M W D$ was defined as $<350 \mathrm{~m}$ in 6 MWT $(8,28)$.

\section{Statistical analyses}

For continuous variables, descriptive statistics were reported as mean \pm standard deviation, whereas categorical variables were reported as a number of patients (\%) per category and the frequency of response. Continuous variables were compared using two-sample $t$-tests, whereas categorical variables were compared using chi-square or Fisher's exact tests, as appropriate. Cubic spline models were used to demonstrate an association between FVC (\% pred) and 6MWD in patients with moderate and severeto-very severe COPD, separately. We used multivariable logistic regression to evaluate the association between FVC and $6 \mathrm{MWD}$, and patients with $\mathrm{FVC} \geq 80 \%$ pred were the reference group. We calculated the adjusted odds ratios (aOR) with progressive degrees of adjustment in patients with moderate and severe-to-very severe COPD, separately: Model 1 was adjusted for age, sex (male vs. female), and smoking status (ever smoker vs. never smoker); Model 2 
included all variables in model 1 plus body mass index (BMI) ( $\geq 25$ vs. $<25 \mathrm{~kg} / \mathrm{m}^{2}$ ); and Model 3 included all variables in model 2 plus history of asthma. We considered a value of $\mathrm{P}<0.050$ as statistically significant. All statistical analyses were performed using STATA 15.1 version (StataCorp LP, College Station, TX, USA).

\section{Results}

\section{Patient characteristics}

The baseline characteristics of the study population are summarized according to COPD severity and FVC category in Table 1. Among moderate COPD patients, those with reduced FVC were more likely to be older $(\mathrm{P}<0.001)$, have higher BMI $(\mathrm{P}<0.001)$, and include fewer smokers $(\mathrm{P}<0.001)$ than those with preserved FVC. However, in patients with severe-to-very severe COPD, there were no statistically significant differences in terms of age, BMI, and smoking status according to the FVC category.

With respect to pulmonary comorbidities, asthma was more common in patients with reduced FVC than in those with preserved FVC ( $\mathrm{P}=0.044$ for moderate COPD, $\mathrm{P}=0.004$ for severe-to-very severe COPD). However, the prevalence of a history of previous tuberculosis infection was not different between the two groups.

With respect to extrapulmonary comorbidities, patients with reduced FVC in the moderate COPD group were more likely to have peripheral vascular disease $(\mathrm{P}=0.002)$, diabetes mellitus $(\mathrm{P}=0.002)$, hypertension $(\mathrm{P}<0.001)$, and dyslipidemia $(\mathrm{P}=0.017)$ than those with preserved FVC.

Among moderate and severe-to-very severe COPD patients, those with reduced FVC were more likely to have a higher BODE index score $(\mathrm{P}<0.001)$ than those with preserved FVC. In contrast, patients with reduced FVC were more likely to have lower $\mathrm{FEV}_{1}$ (L) (\% pred) $(\mathrm{P}<0.001)$ and higher $\mathrm{FEV}_{1} / \mathrm{FVC}$ ratio $(\mathrm{P}<0.001)$ than those with preserved FVC. In addition, patients with reduced FVC were more likely to have shorter 6MWD $(\mathrm{P}<0.001$ for moderate COPD, $\mathrm{P}=0.003$ for severe-to-very severe COPD) than those with preserved FVC. However, there were no statistically significant differences in the $\mathrm{mMRC}$ score, CAT score, and SGRQ-C total score between patients with reduced FVC and those with preserved FVC.

\section{Relationship between FVC and 6MWD in COPD patients}

Figure 2 shows the relationship between FVC (\%pred) and $6 M W D$ evaluated using a cubic spline model. In moderate COPD patients, 6MWD steadily increased up to approximately $93 \%$ pred of FVC and plateaued (Figure $2 A$ ). While, in severe-to-very severe COPD patients, 6MWD steadily increased as FVC (\%pred) increased (Figure 2B). The performance of FVC was comparable with that of $\mathrm{FEV}_{1}$ as a predictor for short 6MWD (area under the receiver operating characteristic curve: 0.682 for FVC, 0.694 for $\mathrm{FEV}_{1}, \mathrm{P}=0.301$ ) (Figure $\mathrm{S} 1$ ). Similarly, as analyzed using multivariable logistic regression, the performance of FVC was comparable with that of $\mathrm{FEV}_{1}$ (Akaike's Information Criterion: 1,500.322 for FVC, 1,491.202 for $\mathrm{FEV}_{1}$ ).

\section{Impact of reduced FVC on 6MWD in moderate and severe-to-very severe COPD patients}

As shown in Table 2, patients with reduced FVC were more likely to have a shorter 6MWD than those with preserved FVC in the moderate COPD group (22.4\% vs. $32.7 \%$; $\mathrm{P}=0.001)$ and in the severe-to-very severe COPD group (36.9\% vs. $46.0 \% ; \mathrm{P}=0.065$ ).

In moderate COPD patients, reduced FVC was significantly associated with short 6MWD [unadjusted OR $=1.68,95 \%$ confidence interval (CI): 1.25-2.27], which was persistent even after adjusting for confounders including age, sex, smoking status, BMI, and asthma (aOR in model 3 $=1.44$, 95\% CI: $1.03-2.02$ ).

In severe-to-very severe COPD, reduced FVC was significantly associated with short 6MWD in the final model, which was adjusted for age, sex, smoking status, BMI, and asthma (aOR $=1.55,95 \% \mathrm{CI}: 1.01-2.40)$.

\section{Discussion}

By using data from the KOCOSS cohort, we evaluated the association between FVC and exercise capacity measured using 6MWT in COPD patients. We observed that reduced FVC was significantly associated with short 6MWD in COPD patients with moderate $(\mathrm{aOR}=1.44,95 \% \mathrm{CI}$ : 1.03-2.02) and severe-to-very severe (aOR $=1.55,95 \% \mathrm{CI}$ : 1.01-2.40) airflow limitations. 6MWD steadily increased in severe-to-very severe COPD patients, whereas the highest $6 \mathrm{MWD}$ value was observed at around $93 \%$ pred of FVC in moderate COPD patients.

Reduced FVC has been reported to have a relationship with low exercise capacity in COPD. However, most previous studies reported that FVC was simply correlated with $6 \mathrm{MWD}$ without considering the severity of COPD 
Table 1 Baseline characteristics $(\mathrm{N}=1,386)$

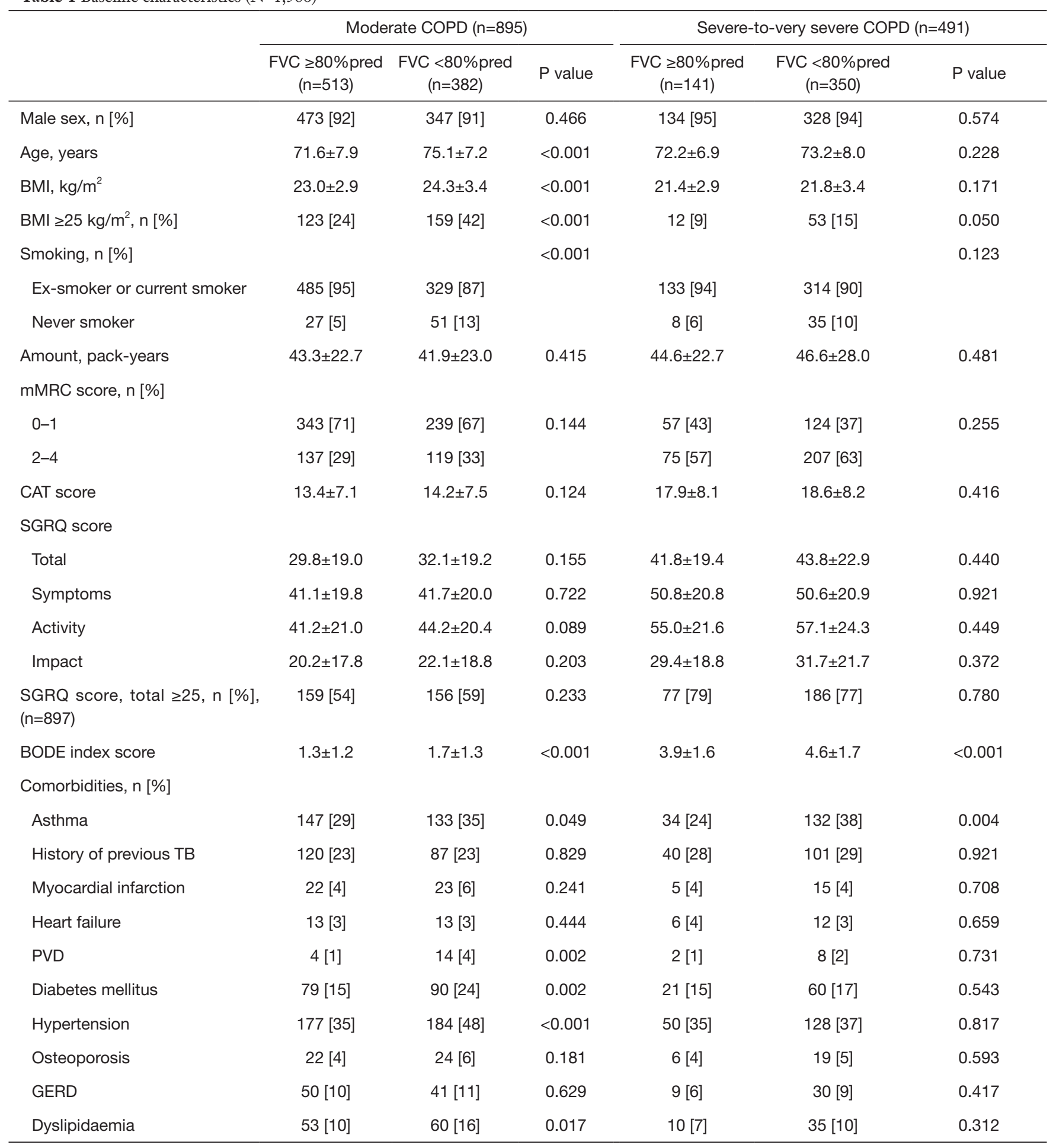

Table 1 (continued) 
Table 1 (continued)

\begin{tabular}{|c|c|c|c|c|c|c|}
\hline & \multicolumn{3}{|c|}{ Moderate COPD $(n=895)$} & \multicolumn{3}{|c|}{ Severe-to-very severe COPD $(n=491)$} \\
\hline FVC, L & $3.73 \pm 0.60$ & $2.85 \pm 0.49$ & $<0.001$ & $3.62 \pm 0.54$ & $2.47 \pm 0.57$ & $<0.001$ \\
\hline $\mathrm{FEV}_{1} \%$ pred & $66.1 \pm 8.4$ & $61.8 \pm 7.3$ & $<0.001$ & $42.2 \pm 5.8$ & $37.6 \pm 7.7$ & $<0.001$ \\
\hline $\mathrm{FEV}_{1} / \mathrm{FVC}$ & $50.1 \pm 8.5$ & $58.1 \pm 7.0$ & $<0.001$ & $32.5 \pm 5.1$ & $42.2 \pm 10.1$ & $<0.001$ \\
\hline DLco & $14.2 \pm 4.5$ & $14.3 \pm 4.6$ & 0.820 & $11.4 \pm 4.5$ & $10.6 \pm 4.0$ & 0.116 \\
\hline \multicolumn{7}{|l|}{ Six-minute walk test } \\
\hline $\mathrm{SpO}_{2}$, after test & $94.6 \pm 4.0$ & $94.5 \pm 7.8$ & 0.720 & $93.0 \pm 4.7$ & $91.7 \pm 7.8$ & 0.080 \\
\hline
\end{tabular}

Two-sample $t$-tests were used for continuous variables, and chi-square or Fisher's exact tests were used for categorical variables. COPD, chronic obstructive pulmonary disease; FVC, forced vital capacity; pred, predicted; BMI, body mass index; mMRC, modified Medical Research Council; CAT, COPD assessment test; SGRQ, St George's respiratory questionnaire; BODE, body mass index, airflow obstruction, dyspnoea, and exercise capacity; TB, tuberculosis; PVD, peripheral vascular disease; GERD, gastroesophageal reflux disease; $\mathrm{FEV}_{1}$, forced expiratory volume in 1 second; $\mathrm{DLco}$, diffusing capacity of the lung for carbon monoxide; $\mathrm{SpO}_{2}$, peripheral oxygen saturation.
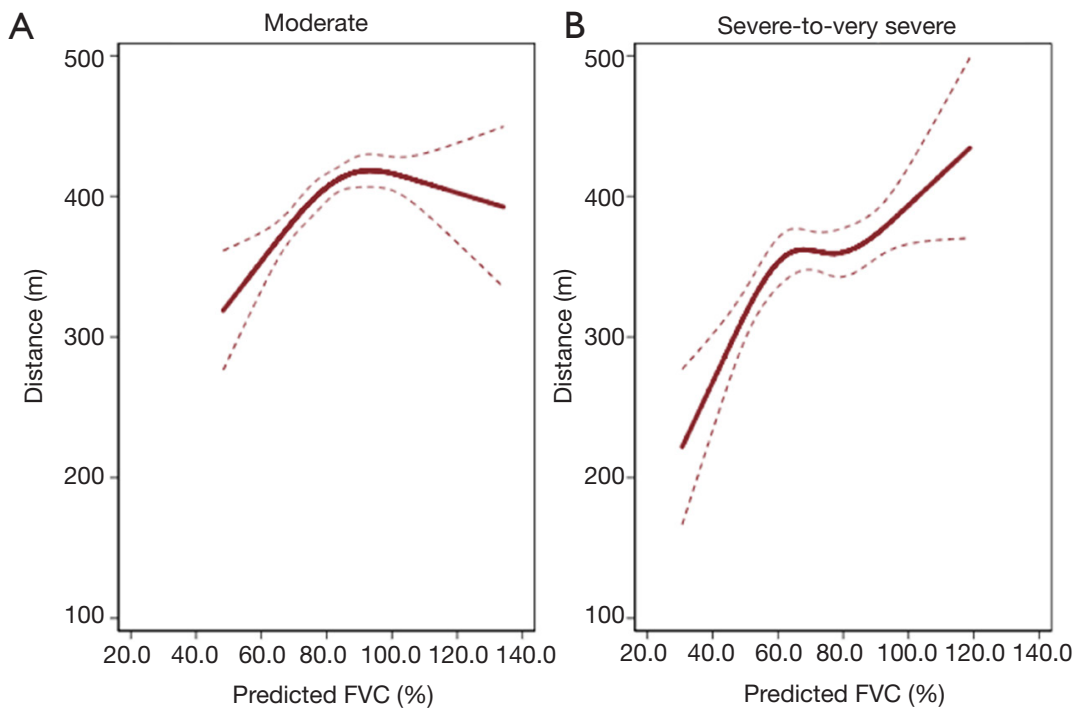

Figure 2 Cubic spline model for the relationship between 6-min walk distance and forced vital capacity, \%predicted in patients with moderate and severe-to-very severe COPD. (A) Relationship in patients with moderate COPD. (B) Relationship in patients with severe-tovery severe COPD. COPD, chronic obstructive pulmonary disease. 
Table 2 Impact of reduced FVC on short 6MWD in patients with moderate COPD and severe-to-very severe COPD

\begin{tabular}{lccccc}
\hline & \multicolumn{2}{c}{ Moderate COPD $(\mathrm{n}=895)$} & & \multicolumn{2}{c}{ Severe-to-very severe COPD $(\mathrm{n}=491)$} \\
\cline { 2 - 3 } \cline { 5 - 6 } & $\begin{array}{c}\mathrm{FVC} \geq 80 \% \text { pred } \\
(\mathrm{n}=115 / 513,22.4 \%)\end{array}$ & $\begin{array}{c}\text { FVC }<80 \% \text { pred } \\
(\mathrm{n}=125 / 382,32.7 \%)\end{array}$ & & $\begin{array}{c}\text { FVC } \geq 80 \% \text { pred } \\
(\mathrm{n}=52 / 141,36.9 \%)\end{array}$ & $\begin{array}{c}\text { FVC }<80 \% \text { pred } \\
(\mathrm{n}=161 / 350,46.0 \%)\end{array}$ \\
\hline Crude & Reference & $1.68(1.25,2.27)$ & Reference & $1.46(0.98,2.18)$ \\
Model 1 & Reference & $1.43(1.03,1.98)$ & Reference & $1.59(1.04,2.45)$ \\
Model 2 & Reference & $1.44(1.03,2.01)$ & Reference & $1.60(1.04,2.46)$ \\
Model 3 & Reference & $1.44(1.03,2.02)$ & Reference & $1.55(1.01,2.40)$ \\
\hline
\end{tabular}

Data are presented as OR and $95 \% \mathrm{Cl}$. Model 1: adjusted for age, sex, and smoking status. Model 2: adjusted for age, sex, smoking status, and body mass index $\geq 25 \mathrm{~kg} / \mathrm{m}^{2}$. Model 3: adjusted for age, sex, smoking status, body mass index $\geq 25 \mathrm{~kg} / \mathrm{m}^{2}$, and asthma. Multivariable logistic regression was used and patients with FVC $\geq 80 \%$ pred were the reference group. FVC, forced vital capacity; pred, predicted; 6MWD, 6-min walk distance; COPD, chronic obstructive pulmonary disease; OR, odds ratio; Cl, confidence interval.

$(18,19,29,30)$. This study revealed the increase patterns were different between moderate COPD group and severeto-very severe COPD group. In patients with moderate COPD, the exercise capacity did not improved beyond $93 \%$ pred of FVC, whereas, in patients with severe-to-very severe COPD, the exercise capacity was positively associated with FVC \% pred in all ranges of FVC \% pred. In a previous study with analysis based on COPD severity using Korea National Health and Nutritional Examination Survey data, reduced FVC was independently associated with behavior restrictions in the population with moderate COPD (21); however, behavior restrictions were assessed using a selfreported questionnaire. We extended this finding with objective measurement, 6MWT, and our data showed that reduced FVC was closely associated with short $6 \mathrm{MWD}$, defined as a $6 \mathrm{MWD}$ of $<350 \mathrm{~m}$, in moderate COPD patients. We also showed that FVC \%pred was associated with 6MWD in severe-to-very severe COPD patients, which was not captured with the self-reported questionnaire for behavior restriction in the previous study (21). Thus, preserved FVC may indicate better exercise capacity even in patients with severe-to-very severe COPD.

We observed that higher FVC was associated with better exercise performance, indicating that higher FVC is an important predictor of better exercise capacity in COPD patients with severe-to-very severe airflow limitation. In COPD patients with moderate airflow limitation, however, exercise capacity steadily increased up to $93 \%$ pred of FVC, and plateaued, suggesting that the role of FVC in estimating exercise capacity would be limited when the FVC reached around $90 \%$ pred. It can be speculated by that $6 \mathrm{MWT}$ might have a ceiling effect (31) which influenced decreased discrimination power in moderate COPD patients with greater than $93 \%$ pred of FVC. Secondly, the relatively small number of moderate COPD patients with greater than $93 \%$ pred of FVC $(n=239)$ may have led to imprecise estimates of 6WMD.

Reduced FVC reflected a mixed pattern with both obstructive and restrictive components or air trapping of obstructive disease $(32,33)$. Given that comorbidities and obesity influence the reduction of FVC in COPD patients $(21,34,35)$, the higher prevalence of comorbidities and BMI in moderate COPD patients could affect reduced FVC, leading to a mixed disorder of lung function. Reduced FVC could also be associated with air-trapping-related pseudorestriction (33); however, lung volume measurement data were partly $(64 \%, 573 / 895)$ of moderate COPD, $55 \%$ (268/491) of severe-to-very severe COPD obtained in this study to identify hyperinflation and air trapping (33). Further studies with a measurement of total lung capacity might be helpful for further characterization of the underlying aetiologies of reduced FVC in COPD patients (36).

The relevance of short $6 \mathrm{MWD}$, defined as $<350 \mathrm{~m}$, has been emphasized in the previous studies $(8,28)$. Below the threshold of $350 \mathrm{~m}, 6 \mathrm{MWD}$ was associated with increased risks of mortality, hospitalizations, and exacerbations $(8,37)$. Accordingly, patients with reduced FVC showed higher BODE index scores than those with preserved FVC despite the similar mMRC score and higher BMI. Considering that symptoms quantified using mMRC, CAT, and SGRQ were similar between patients with reduced FVC and those with preserved $\mathrm{FVC}$, clinicians need to pay more attention to impairment in $\mathrm{FVC}$ in addition to $\mathrm{FEV}_{1}$ to predict exercise capacity and other outcomes. 
This study has several limitations. First, the data were obtained from the cross-sectional KOCOSS cohort; therefore, the directionality of the relationship between reduced FVC and poor exercise capacity is uncertain. Further clinical studies with longitudinal follow-up are needed to confirm our observations. Second, as most of the patients were men with a history of smoking, it is difficult to generalize the results from this study to non-smokers or women with COPD. Last, potential confounding factors which could affect on FVC such as interstitial lung disease and cardiac disease could not be thoroughly investigated in this study due to lack of disease severity-related data such as chest computed tomography and echocardiography in the cohort. Further comprehensive evaluations are warranted.

\section{Conclusions}

In conclusion, reduced FVC is significantly associated with short 6MWD in moderate-to-very severe COPD, suggesting that reduced FVC might be reflective of exercise capacity measured by $6 \mathrm{MWD}$. Further studies on the clinical relevance of reduced FVC are warranted.

\section{Acknowledgments}

Funding: This work was supported by the Research Program funded Korea National Institute of Health (Fund CODE: 2016ER670100, 2016ER670101, 2016ER670102, 2018ER67100, 2018ER67101 and 2018ER67102).

\section{Footnote}

Data Sharing Statement: Available at http://dx.doi. org/10.21037/jtd-20-1098a.

Conflicts of Interest: All authors have completed the ICMJE uniform disclosure form (available at http://dx.doi. org/10.21037/jtd-20-1098a). KSJ serves as an unpaid editorial board member of Fournal of Thoracic Disease. The authors have no other conflicts of interest to declare.

Ethical Statement: The authors are accountable for all aspects of the work in ensuring that questions related to the accuracy or integrity of any part of the work are appropriately investigated and resolved. The study was conducted in accordance with the Declaration of Helsinki (as revised in 2013). Written informed consent was obtained from all study patients. Ethics approval for this study was obtained from the institutional review boards of each center (Samsung Medical Center, IRB No. 2014-06-132).

Open Access Statement: This is an Open Access article distributed in accordance with the Creative Commons Attribution-NonCommercial-NoDerivs 4.0 International License (CC BY-NC-ND 4.0), which permits the noncommercial replication and distribution of the article with the strict proviso that no changes or edits are made and the original work is properly cited (including links to both the formal publication through the relevant DOI and the license). See: https://creativecommons.org/licenses/by-nc-nd/4.0/.

\section{References}

1. ZuWallack R, Esteban C. Understanding the impact of physical activity in COPD outcomes: moving forward. Eur Respir J 2014;44:1107.

2. Garcia-Aymerich J, Lange P, Benet M, et al. Regular physical activity reduces hospital admission and mortality in chronic obstructive pulmonary disease: a population based cohort study. Thorax 2006;61:772.

3. Waschki B, Kirsten A, Holz O, et al. Physical activity is the strongest predictor of all-cause mortality in patients with COPD: a prospective cohort study. Chest 2011;140:331-42.

4. Esteban C, Quintana JM, Aburto M, et al. Impact of changes in physical activity on health-related quality of life among patients with COPD. Eur Respir J 2010;36:292.

5. Vaes AW, Garcia-Aymerich J, Marott JL, et al. Changes in physical activity and all-cause mortality in COPD. Eur Respir J 2014;44:1199.

6. Janaudis-Ferreira T, Beauchamp MK, Goldstein RS, et al. How should we measure arm exercise capacity in patients with COPD? A systematic review. Chest 2012;141:111-20.

7. Kerti M, Balogh Z, Kelemen K, et al. The relationship between exercise capacity and different functional markers in pulmonary rehabilitation for COPD. Int J Chron Obstruct Pulmon Dis 2018;13:717-24.

8. Celli B, Tetzlaff K, Criner G, et al. The 6-minute-walk distance test as a chronic obstructive pulmonary disease stratification tool. Insights from the COPD biomarker qualification consortium. Am J Respir Crit Care Med 2016;194:1483-93.

9. Holland AE, Spruit MA, Troosters T, et al. An official European Respiratory Society/American Thoracic Society technical standard: field walking tests in chronic 
respiratory disease. Eur Respir J 2014;44:1428-46.

10. Singh SJ, Puhan MA, Andrianopoulos V, et al. An official systematic review of the European Respiratory Society/ American Thoracic Society: measurement properties of field walking tests in chronic respiratory disease. Eur Respir J 2014;44:1447-78.

11. Global Initiative for Chronic Obstructive Lung Disease (GOLD). Global strategy for the diagnosis, management, and prevention of chronic obstructive pulmonary disease. 2019.

12. Godfrey MS, Jankowich MD. The vital capacity is vital: epidemiology and clinical significance of the restrictive spirometry pattern. Chest 2016;149:238-51.

13. Lee HM, Le H, Lee BT, et al. Forced vital capacity paired with Framingham Risk Score for prediction of all-cause mortality. Eur Respir J 2010;36:1002-6.

14. Nakajima K, Kubouchi Y, Muneyuki T, et al. A possible association between suspected restrictive pattern as assessed by ordinary pulmonary function test and the metabolic syndrome. Chest 2008;134:712-8.

15. Vaz Fragoso CA, McAvay G, Van Ness PH, et al. Phenotype of spirometric impairment in an aging population. Am J Respir Crit Care Med 2016;193:727-35.

16. Oga T, Nishimura K, Tsukino M, et al. Analysis of the factors related to mortality in chronic obstructive pulmonary disease: role of exercise capacity and health status. Am J Respir Crit Care Med 2003;167:544-9.

17. Puente-Maestu L, Palange P, Casaburi R, et al. Use of exercise testing in the evaluation of interventional efficacy: an official ERS statement. Eur Respir J 2016;47:429-60.

18. Bell M, Fotheringham I, Punekar YS, et al. Systematic review of the association between laboratory- and fieldbased exercise tests and lung function in patients with chronic obstructive pulmonary disease. Chronic Obstr Pulm Dis 2015;2:321-42.

19. Kundu A, Maji A, Sarkar S, et al. Correlation of six minute walk test with spirometric indices in chronic obstructive pulmonary disease patients: A tertiary care hospital experience. J Assoc Chest Physicians 2015;3:9.

20. Pepin V, Brodeur J, Lacasse Y, et al. Six-minute walking versus shuttle walking: responsiveness to bronchodilation in chronic obstructive pulmonary disease. Thorax 2007;62:291-8.

21. Kang N, Shin SH, Gu S, et al. The impact of low forced vital capacity on behavior restrictions in a population with airflow obstruction. J Thorac Dis 2019;11:1316-24.

22. Jones PW, Adamek L, Nadeau G, et al. Comparisons of health status scores with MRC grades in COPD: implications for the GOLD 2011 classification. Eur Respir
J 2013;42:647-54.

23. Jones PW, Harding G, Berry P, et al. Development and first validation of the COPD Assessment Test. Eur Respir J 2009;34:648-54.

24. Meguro M, Barley EA, Spencer S, et al. Development and validation of an improved, COPD-specific version of the St. George Respiratory Questionnaire. Chest 2007;132:456-63.

25. Rhee CK, Yoo KH, Lee JH, et al. Clinical characteristics of patients with tuberculosis-destroyed lung. Int J Tuberc Lung Dis 2013;17:67-75.

26. Miller MR, Hankinson J, Brusasco V, et al. Standardisation of spirometry. Eur Respir J 2005;26:319-38.

27. Laboratories ACoPSfCPF. ATS statement: guidelines for the six-minute walk test. Am J Respir Crit Care Med 2002;166:111-7.

28. Celli BR, Cote CG, Marin JM, et al. The body-mass index, airflow obstruction, dyspnea, and exercise capacity index in chronic obstructive pulmonary disease. N Engl J Med 2004;350:1005-12.

29. Agrawal MB, Awad NT. Correlation between six minute walk test and spirometry in chronic pulmonary disease. J Clin Diagn Res 2015;9:OC01-4.

30. Awotidebe TO, Awopeju OF, Bisiriyu LA, et al. Relationships between respiratory parameters, exercise capacity and psychosocial factors in people with chronic obstructive pulmonary disease. Ann Phys Rehabil Med 2017;60:387-92.

31. Puente-Maestu L, Stringer W, Casaburi R. Exercise testing to evaluate therapeutic interventions in chronic respiratory diseases. BRN Rev 2018;4:274-86.

32. Landsberg JW. Pulmonary function testing. In: Clinical Practice Manual for Pulmonary and Critical Care Medicine: Elsevier, 2018:22-35.

33. Culver BH. Pulmonary function testing. In: Clinical Respiratory Medicine, 4th edition: Elsevier, 2012:133-42.

34. Leone N, Courbon D, Thomas F, et al. Lung function impairment and metabolic syndrome: the critical role of abdominal obesity. Am J Respir Crit Care Med 2009;179:509-16.

35. Kang HK, Park HY, Jeong BH, et al. Relationship between forced vital capacity and Framingham cardiovascular risk score beyond the presence of metabolic syndrome: the fourth Korea national health and nutrition examination survey. Medicine (Baltimore) 2015;94:e2089.

36. Lee H, Chang B, Kim K, et al. Clinical utility of additional measurement of total lung capacity in diagnosing obstructive lung disease in subjects with restrictive pattern 
of spirometry. Respir Care 2016;61:475-82.

37. Durheim MT, Smith PJ, Babyak MA, et al. Six-minutewalk distance and accelerometry predict outcomes in chronic obstructive pulmonary disease independent of global initiative for chronic obstructive lung disease 2011 Group. Ann Am Thorac Soc 2015;12:349-56.

Cite this article as: Moon SM, Lim JH, Hong YS, Shin KC, Lee CY, Kim DJ, Lee SH, Jung KS, Lee CH, Yoo KH, Lee H, Park HY. Clinical impact of forced vital capacity on exercise performance in patients with chronic obstructive pulmonary disease. J Thorac Dis 2021;13(2):837-846. doi: 10.21037/jtd-20$1098 \mathrm{a}$ 


\section{Supplementary}

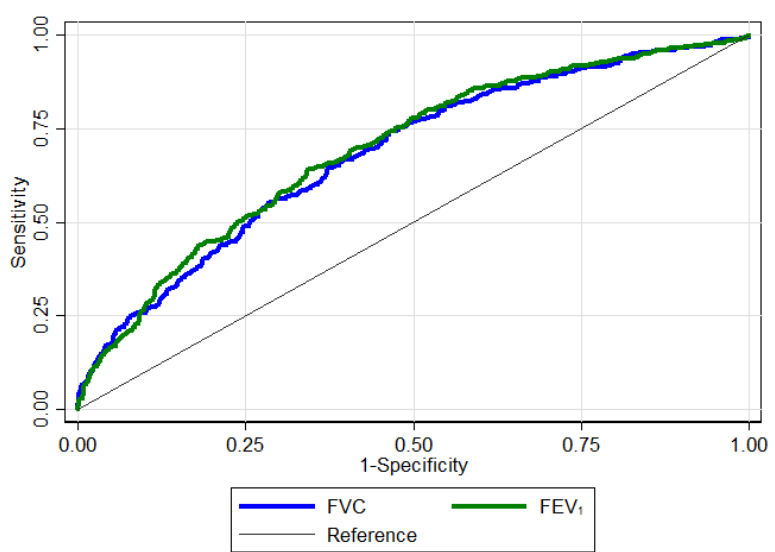

Figure S1 ROC curves for the detection of short 6-min walk distance. Area under the ROC curves were similar ( 0.6823 for FVC; 0.6935 for $\mathrm{FEV}_{1}$ ) between two measures $(\mathrm{P}=0.301)$. ROC, receiver operating characteristic; $\mathrm{FVC}$, forced vital capacity; $\mathrm{FEV} 1$, forced expiratory volume in 1 second. 